IOS Press

\title{
Review
}

\section{"PROBE"ing the Role of Cytoreductive Nephrectomy in Advanced Renal Cancer}

\author{
Hannah Bell ${ }^{\mathrm{a}}$, Brittney H. Cotta ${ }^{\mathrm{b}}$, Simpa S. Salami ${ }^{\mathrm{b}, \mathrm{c}, \mathrm{d}}$, Hyung Kim ${ }^{\mathrm{e}}$ and Ulka Vaishampayan ${ }^{\mathrm{d}, \mathrm{e}, \mathrm{f}, *}$ \\ ${ }^{a}$ University of Michigan School of Medicine, Ann Arbor, MI, USA \\ ${ }^{\mathrm{b}}$ Department of Urology, University of Michigan, Ann Arbor, MI, USA \\ ${ }^{\mathrm{c} M i c h i g a n}$ Center for Translational Pathology, Michigan Medicine, Ann Arbor, MI, USA \\ ${ }^{\mathrm{d}}$ University of Michigan Rogel Cancer Center, Ann Arbor, MI, USA \\ e Division of Urology, Cedars Sinai Cancer Center, Los Angeles, CA, USA \\ ${ }^{\mathrm{f}}$ Department of Medicine/Oncology, University of Michigan, Ann Arbor, MI, USA
}

Received 28 November 2021

Accepted 17 December 2021

Pre-press 30 December 2021

Published 15 March 2022

\begin{abstract}
The Southwest Oncology Group (SWOG)1931 trial, also known as PROBE (ClinicalTrials.gov Identifier: NCT04510597) is a phase III study evaluating the role of cytoreductive nephrectomy $(\mathrm{CN})$ in metastatic renal cell cancer (RCC). Kidney cancer presenting with synchronous metastases has demonstrated shorter survival outcome compared to the patients relapsing with metastases after nephrectomy. Previously, $\mathrm{CN}$ has been associated with survival improvement when interferon-based systemic therapy was used. In the setting of antivascular therapy sunitinib, a prospective randomized clinical trial demonstrated no benefit of CN. Immune checkpoint-based combination therapy has now become the standardof-care in the frontline setting for RCC. The role of nephrectomy or primary resection has not been evaluated in the setting of immune checkpoint-based systemic therapy. The sequence and optimal timing of nephrectomy is also not established. The PROBE study design attempts to answer the question whether $\mathrm{CN}$ has an impact on overall survival outcomes in RCC within the context of immune checkpoint-based combination regimens. The study requires starting with systemic therapy; any one of the FDA approved immunotherapy-based regimens at the time the study was activated are permitted. The disease status and response are evaluated at 9-12 weeks of therapy and then consented patients are randomized 1:1 to receive $\mathrm{CN}$ or to continue systemic therapy. The patients who have rapid disease progression are considered ineligible for randomization as they need a switch in systemic therapy. Both groups should continue systemic therapy as long as they are tolerating the treatment and continuing to derive clinical benefit. Quality-of-life, tumor genomic testing, microbiome, radiomics and circulating tumor DNA assessments as predictive biomarkers are planned as study correlatives.

The study hypothesis is that $\mathrm{CN}$ will improve $\mathrm{OS}$ in synchronous metastatic RCC when surgery is performed after starting systemic immune checkpoint-based combination therapy. A potential mechanism leading to improved survival is the broader antigen spread and higher neoantigen load enabled by the primary tumor enhancing the efficacy of the immune therapy. CN after initial systemic therapy would help select the patient subset most likely to benefit and will potentially enable eradication of immune resistant clones within the primary tumor.
\end{abstract}

\footnotetext{
${ }^{*}$ Correspondence to: Ulka Vaishampayan, MD, 7217 Rogel Cancer Center, SPC5948, 1500 E. Medical Ctr Dr. Ann Arbor, MI 48109, USA. Tel.: +1 734936 7813; Fax: +1 734647 9480; E-mail: vaishamu@med.umich.edu.
}

\section{INTRODUCTION}

Synchronous metastatic renal cell carcinoma (RCC) is a subset comprising 30-40\% of the patients diagnosed with advanced disease. Within advanced 
RCC, this subset is expected to have worse outcomes and is least studied in clinical trials. Traditionally, all therapeutic clinical trials in advanced RCC have included patients post nephrectomy and the initial trials of sunitinib even required nephrectomy as an eligibility criterion. It is important to evaluate the role of immune checkpoint inhibition therapy and of cytoreductive nephrectomy $(\mathrm{CN})$ in $\mathrm{RCC}$ presenting with synchronous metastases.

Previous phase III trials demonstrated that cytoreductive removal of the primary tumor can improve overall survival in advanced kidney cancer. The role of $\mathrm{CN}$ has been evaluated in the settings of interferon therapy and sunitinib therapy. However, no such assessment is available in the setting of contemporary immune checkpoint inhibitor (ICI) based regimens. Therefore, as ICI combinations become the mainstay of therapy in kidney cancer, the role of surgical intervention needs to be reassessed. There is evidence from two randomized multicenter phase III trials that $\mathrm{CN}$ extends overall survival (OS) for patients with metastatic RCC (mRCC) treated with cytokine-based immunotherapy [1-3]. However, the more recently reported CARMENA Trial showed that for patients treated with sunitinib monotherapy, OS in the non-nephrectomy group was not inferior to the group that was first treated with $\mathrm{CN}$ [4]. Although there were several key differences between these trials, it is possible that cytoreduction is beneficial in patients treated with immune-based therapies but not in patients receiving only targeted therapies where the mechanism of action involves anti-angiogenesis. This proposal evaluates the role of $\mathrm{CN}$ in the setting of contemporary ICI-based therapy.

Advanced renal cancer has multiple therapy options and new regimens are attaining standard therapy status rapidly with improved efficacy. As the frontline therapies develop with incremental advances, it has become important to focus on the subgroups that are not gaining optimal benefit and have worse clinical outcomes. Of those, patients presenting with synchronous renal mass and metastases are a dominant group. This subset of advanced renal cancer has shorter OS even with utilization of contemporary ICI-based therapies. In Checkmate-214, the median survival of the group presenting with synchronous metastases was 24 months as compared to 48 months for all patients on the study [5]. [Table 1] The dilemma of whether to perform cytoreductive nephrectomy in cases presenting with synchronous metastases has emerged. The immune mechanism of systemic therapy is expected to have a distinct impact on metastases with enhancement of response initially with the primary tumor in place and subsequent eradication of resistant clones with surgical resection.

\section{CYTOREDUCTIVE NEPHRECTOMY IN SYNCHRONOUS METASTATIC RCC}

Most of the early clinical trials of novel agents excluded patients who did not have a prior nephrectomy. This is the best selection mechanism to enroll patients likely to have the best outcome with systemic therapy. Four prospective randomized trials have been reported primarily addressing the role of $\mathrm{CN}$ in metastatic RCC. SWOG 8949 was a study that randomized synchronous metastatic RCC patients to upfront nephrectomy followed by interferon versus systemic therapy alone [1]. The study showed a statistically significant improvement in overall survival in the CN arm. Similar results were reported in an EORTC trial [2]. The response to interferon therapy remained 3\% in both arms. The possible mechanism was postulated that $\mathrm{CN}$ helped eradicate some of the resistant clones of disease and enabled improved outcomes to systemic therapy. The anti-vascular therapy sunitinib was proven to be superior to interferon in advanced RCC and was FDA approved in 2006 [6]. The CARMENA trial [4] was conducted with the objective of evaluating the role of $\mathrm{CN}$ in conjunction with sunitinib therapy [Table 2]. Interestingly, the study showed that with improved efficacy of systemic therapy (sunitinib), the initial CN no longer had a relevant impact on outcomes. Subset analysis of intermediate and poor risk groups revealed that $\mathrm{CN}$ did not benefit either group. With the advent of VEGF-TKI therapy which has improved efficacy over interferon, the incremental benefit of $\mathrm{CN}$ was not clinically relevant. In addition, $\mathrm{CN}$ had the potential for complications such as bleeding, renal dysfunction and other anesthesia related and operative morbidities. Perhaps the largest drawback to upfront nephrectomy in the setting of effective systemic therapy, was that about $20 \%$ of the patients were unable to receive systemic therapy due to clinical deterioration after nephrectomy.

The CARMENA trial results led ASCO to declare the Advance of the Year as "Refinement of Surgical Treatment of Kidney Cancer: Surgical resection has traditionally been the primary treatment of many solid tumors, including RCC. Results from two randomized controlled trials [4, 7] provided evidence for targeted therapy-based approaches that might eliminate the need for surgery in this type of cancer." 
Table 1

Nephrectomy Status in Phase III Trials of FDA Approved Immune Checkpoint

Based Combination Regimens in Advanced RCC

\begin{tabular}{|c|c|c|}
\hline Study Type and Arm & $\begin{array}{l}\text { All Patients (ITT) } \\
\text { ORR/med PFS/med OS }\end{array}$ & Nephrectomy Status \\
\hline Checkmate -214 [11] & 1096 patients & No Nephrectomy 84 (19.7\%) \\
\hline Ipi + nivo & $42.1 \% / 11.2 \mathrm{mths} / 48 \mathrm{mths}$ & ORR 34\%/median OS :26 months \\
\hline Sunitinib & $26.3 \% / 8.3 \mathrm{mths} / 26 \mathrm{mths}$ & $\begin{array}{l}\text { No Nephrectomy } 103(24.4 \%) \\
\text { ORR } 14.5 \% / \text { median OS: } 14 \text { months }\end{array}$ \\
\hline Keynote 426 [9] & 861 patients & No Nephrectomy 146 (16.9\%) \\
\hline Axi + pembro & $59.3 \% / 15.1 \mathrm{mths} / 45.7 \mathrm{mths}$ & $75 / 432(17.3 \%)$ \\
\hline Sunitinib & $35.7 \% / 11.1 \mathrm{mths} / 40.1 \mathrm{mths}$ & $71 / 429(16.5 \%)$ \\
\hline Javelin-101 [10] & 886 patients & Nephrectomy \\
\hline Axi + Avelumab & $55.2 \% / 13.8 \mathrm{mths} / \mathrm{OS} \mathrm{NR}$ & Yes $485(86.7 \%)$ HR 0.63 \\
\hline Sunitinib & $\begin{array}{l}25.5 \% / 8.4 \mathrm{mths} / \mathrm{OS} \mathrm{NR} \\
\text { No OS benefit }\end{array}$ & $\begin{array}{l}95 \% \text { CI } 0.48-0.82 \\
\text { No } 75(13.3 \%) \text { HR }=0.63 \\
95 \% \text { CI } 0.31-1.29\end{array}$ \\
\hline Checkmate 9ER [8] & 651 patients & Nephrectomy \\
\hline Cabo + nivo & $55.7 \% / 16.6 \mathrm{mths} / \mathrm{NR}$ & $\begin{array}{l}\text { Yes } 455(70 \%) \text { HR } 0.46 \\
95 \% \text { CI } 0.35-0.60\end{array}$ \\
\hline Sunitinib & $\begin{array}{l}27.1 \% / 8.3 \text { months/NR } \\
\mathrm{HR}=0.6 \text { for } \mathrm{OS} \\
\mathrm{P}=0.001\end{array}$ & $\begin{array}{l}\text { No }(30 \%) \text { HR }=0.63 \\
95 \% \text { CI } 0.43-0.92\end{array}$ \\
\hline CLEAR trial [12] & 1069 patients & No nephrectomy 272 patients $(25.4 \%)$ \\
\hline Len + Pembro & $71 \% / 23.9 \mathrm{mths} / \mathrm{NR}$ & $97 / 355(26.1 \%)$ \\
\hline Len + Eve & $53.5 \% / 14.9 \mathrm{mths} / \mathrm{NR}$ & $97 / 357(27 \%)$ \\
\hline Sunitinib & $\begin{array}{l}36.1 \% / 9.2 \mathrm{mths} / \mathrm{NR} \\
\mathrm{Len}+\text { pembro vs sunitinib } \\
\mathrm{HR}=0.66 \text { for OS } \\
\mathrm{P}=0.005\end{array}$ & $82 / 357(22.9 \%)$ \\
\hline
\end{tabular}

Table 2

Retrospective and Prospective Data in Synchronous Metastatic RCC

\begin{tabular}{|c|c|c|c|}
\hline Study & $\begin{array}{l}\text { Type } \\
\text { Sample Size }\end{array}$ & Arms /Response rates & OS \\
\hline S8949 & $\begin{array}{l}\text { Prospective } \\
250\end{array}$ & $\begin{array}{l}\text { Interferon } / 4 \% \\
\mathrm{CN}+\text { interferon } / 3 \%\end{array}$ & $\begin{array}{l}\text { Median } 8.1 \text { months } \\
\text { Median } 12.5 \text { months } \\
P=0.006\end{array}$ \\
\hline EORTC & $\begin{array}{l}\text { Prospective } \\
85\end{array}$ & $\begin{array}{l}\text { Interferon } \\
\mathrm{CN}+\text { interferon }\end{array}$ & $\begin{array}{l}\text { Median } 7 \text { months } \\
\text { Median } 17 \text { months } \\
\text { HR }=0.54 \\
95 \% \text { CI } 0.31-0.94\end{array}$ \\
\hline CARMENA [4] & $\begin{array}{l}\text { Prospective } \\
450\end{array}$ & $\begin{array}{l}\text { Sunitinib } \\
\mathrm{CN}+\text { sunitinib }\end{array}$ & $\begin{array}{l}\text { Median } 18.4 \text { months } \\
\text { Median } 13.9 \text { months } \\
\text { HR }=0.89 \\
95 \% \text { CI } 0.71-1.10\end{array}$ \\
\hline SURTIME [7] & $\begin{array}{l}\text { Prospective } \\
99\end{array}$ & $\begin{array}{l}\text { Initial nephrectomy } \\
\text { Deferred Nephrectomy }\end{array}$ & $\begin{array}{l}\text { Median } 15 \text { months } \\
\text { Median } 32.4 \text { months } \\
\text { HR }=0.57, p=0.03 \\
95 \% \text { CI } 0.34-0.95\end{array}$ \\
\hline IMDC [13] & $\begin{array}{l}\text { Retrospective } \\
1658 \text { patients }\end{array}$ & $\begin{array}{l}\text { Targeted therapy (676) } \\
\text { CN + Targeted therapy (982) }\end{array}$ & $\begin{array}{l}\text { Median } 9.5 \text { months } \\
\text { Median } 20.6 \text { months } \\
P<0.0001\end{array}$ \\
\hline ReNIS [14] & $\begin{array}{l}\text { Retrospective } \\
750\end{array}$ & $\begin{array}{l}\text { Targeted therapy (272) } \\
\text { CN + Targeted therapy (458) }\end{array}$ & $\begin{array}{l}\text { Median } 14.2 \text { months } \\
\text { Median } 27.2 \text { months } \\
\text { HR }=0.6, P<0.001 \\
95 \% \text { CI } 0.52-0.69\end{array}$ \\
\hline SEER [15] & $\begin{array}{l}\text { Retrospective } \\
21052\end{array}$ & $\begin{array}{l}\text { No CN }(63 \%) \\
\text { CN performed (37\%) }\end{array}$ & $\begin{array}{l}\text { Median } 3.0 \text { months } \\
\text { Median } 18.0 \text { months } \\
\text { HR }=0.31 \\
95 \% \text { CI } 0.30-0.33\end{array}$ \\
\hline
\end{tabular}


The SURTIME trial [7] explored the question of optimal timing of nephrectomy. The study randomized RCC cases with synchronous metastasis to initial $\mathrm{CN}$ followed by sunitinib versus $\mathrm{CN}$ following 12 weeks of sunitinib therapy. The results reported no difference in outcomes for the primary endpoint of 28 week progression free survival (PFS); however, OS almost doubled in the deferred $\mathrm{CN}$ arm [Median of 15 months vs 32.4 months $p=0.03$, hazard ratio $=0.57$ ] and about $20 \%$ of the patients in the immediate nephrectomy arm did not receive sunitinib therapy.

The arrival of ICI based regimens boosted the efficacy of systemic therapy in kidney cancer even further. Five distinct regimens have demonstrated improved PFS and response rates and four of these have demonstrated OS benefit in comparison with sunitinib as the control arm. The proportion of patients who did not have nephrectomy in these studies is low. Checkmate 9ER [8] enrolled the highest proportion of patients without nephrectomy at about 30\%. Keynote 426 [9] and Javelin-101 [10] enrolled $17 \%$ and $13 \%$ non-nephrectomy patients, respectively. About $22 \%$ of patients enrolled on Checkmate-214 [11] and $20 \%$ on the CLEAR trial [12] did not undergo nephrectomy.

Retrospective trials [Table 2] have endorsed the advantage of debulking nephrectomy despite the presence of metastatic disease, in context of either cytokine or VEGF TKI based therapies [13-15]. Patient selection-bias was a large factor in the retrospective data series and prospective clinical trials have revealed the lack of benefit from initial $\mathrm{CN}$ in metastatic disease treated with sunitinib therapy. However, the role of $\mathrm{CN}$ in the setting of ICI regimens remains to be determined. Preclinical data indicates that the approach of initial I-O based therapy followed by $\mathrm{CN}$ is likely to impart clinical benefit. S1931/PROBE trial is attempting to answer this question and is evaluating whether $\mathrm{CN}$ has a role in management of metastatic RCC within the setting of contemporary immune based combination therapy [Fig. 1].

\section{IMMUNE BASED COMBINATION THERAPIES IN ADVANCED RCC}

Checkpoint inhibitors comprise a class of immunotherapy that is FDA approved for a broad range of malignancies, including RCC. The study Checkmate 214 established superior efficacy of ipilimumab (ipi) plus nivolumab (nivo) over sunitinib, demonstrating OS benefit for patients with previously untreated metastatic renal cancer [11]. This regimen

\section{Two Opportunities to Enroll:}

\section{Treatment Naïve Patients}

Register to study \& receive prerandomization immunotherapy on study
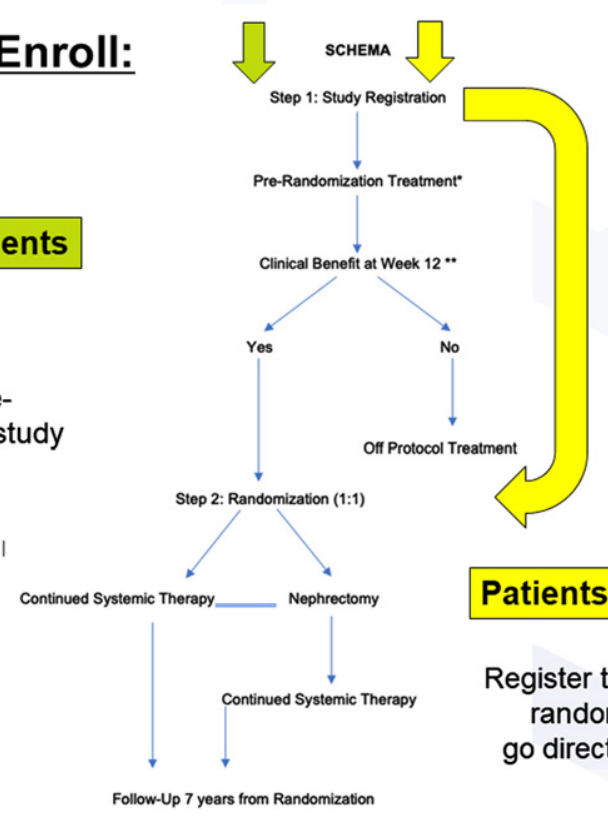

Patients who started Treatment

Register to study after completing prerandomization immunotherapy; go directly to randomized treatment 
(nivolumab, $3 \mathrm{mg}$ per kilogram of body weight, plus ipilimumab, $1 \mathrm{mg}$ per kilogram of body weight every 3 weeks for four doses followed by nivolumab, $3 \mathrm{mg}$ per kilogram, every 2 weeks) is now approved by the FDA for intermediate and poor risk mRCC. In this study $24 \%$ of the patients did not have $\mathrm{CN}$ and subgroup analysis revealed that the hazard ratio of benefit for ipilimumab + nivolumab $(I+N)$ over sunitinib was maintained regardless of nephrectomy status.

In CheckMate 214, 1096 patients with newly diagnosed metastatic RCC were randomly assigned to receive $\mathrm{I}+\mathrm{N}$ or sunitinib. Co-primary end points were OS, objective response rate, and PFS among patients with intermediate or poor prognostic risk as defined by International Metastatic Renal Cell Carcinoma Database Consortium (IMDC); 425 and 422 had intermediate and poor risk, respectively. The 18month OS was $75 \%$ with $\mathrm{I}+\mathrm{N}$ versus $60 \%$ with sunitinib $(P<0.001)$. The median OS was 48 months with $\mathrm{I}+\mathrm{N}$ and it was 26.0 months with sunitinib (hazard ratio for death, $0.63 ; 99.8 \%$ CI were $0.44-$ 0.89 ). The objective response rates were $42 \%$ versus $27 \%(P<0.001)$ with complete response rates of $9 \%$ versus $1 \%$, respectively. The median PFS was 11.6 months and 8.4 months, respectively (hazard ratio for disease progression or death, $0.82 ; p=0.03$ ). The drugs were well tolerated in both treatment groups. Adverse events occurred in 509 of 547 patients (93\%) in the $\mathrm{I}+\mathrm{N}$ group and 521 of 535 patients $(97 \%)$ in the sunitinib group. Grade 3 or 4 events occurred in 250 patients (46\%) and 335 patients (63\%), respectively. Treatment-related adverse events leading to discontinuation occurred in $22 \%$ and $12 \%$ of the patient groups, respectively. Based on these results, the FDA has approved ipilimumab and nivolumab for intermediate or poor risk metastatic RCC.

In Checkmate 214 about $24 \%$ of the patients had their primary tumor in place and in this subgroup the HR favoring $\mathrm{I}+\mathrm{N}$ was $0.63(0.42-0.94)$. SEER data analysis reveals that majority $(63 \%)$ of $\mathrm{mRCC}$ patients do not undergo $\mathrm{CN}$ as their initial management, however the non-nephrectomy patients are a minority $(<30 \%)$ in therapeutic clinical trials [15]. Therefore, the PROBE trial will provide an opportunity to characterize treatment outcomes in a patient population that has been underrepresented in prior RCC trials.

Combination of VEGF-TKI axitinib and immune checkpoint inhibitor therapy has demonstrated benefit in front line therapy of advanced RCC and has received FDA approval. Keynote 426 [9] established superior efficacy of pembrolizumab plus axitinib over sunitinib for patients with previously untreated metastatic clear cell RCC and led to FDA approval of the combination regimen. Keynote 426 randomized 861 patients to receive $200 \mathrm{mg}$ pembrolizumab IV every 3 weeks and $5 \mathrm{mg}$ axitinib orally twice daily or standard dose of sunitinib. In the group receiving pembrolizumab and axitinib, the objective response rate was $59.5 \%$, the median PFS was 15.1 months, and 12 month-survival rate was $89.9 \%$. In the control group, the objective response rate was $35.7 \%$ $(p<0.001)$, median PFS was 11.1 months (hazard ratio $0.69 ; p<0.001)$, and 12 month-survival rate was $78.3 \%$ (hazard ratio $0.53 ; p<0.0001$ ). The benefit of pembrolizumab plus axitinib was observed across intermediate and poor risk groups and regardless of programmed death ligand 1 (PD-L1) expression. Grade 3 or higher adverse events of any cause occurred in $75.8 \%$ of patients in the study group and $70.6 \%$ of patients in the control group.

Javelin 101 [10] established superior efficacy of avelumab plus axitinib over sunitinib for patients with previously untreated metastatic clear cell RCC and led to FDA approval of the combination regimen. This study randomized 886 patients in all IMDC risk groups to receive avelumab (10mg per $\mathrm{kg}$ of body weight) IV every 2 weeks and $5 \mathrm{mg}$ axitinib orally twice daily or standard dose of sunitinib. The primary endpoints for the study were PFS and OS among patients with PD-L1-positive tumors. Among patients with PD-L1-positive tumors, the median PFS and overall response rate were 13.8 months and $55.2 \%$ in the combination treatment group and 7.2 months (hazard ratio $0.61 ; p<0.001$ ) and $25.5 \%$ (odds ratio for RR 3.73; 95\% CI, 2.53 to 5.37) in the control group. In the overall population, the median PFS and overall response rate were 13.8 months and $51.4 \%$ in the experimental group and 8.4 months (hazard ratio $0.69 ; p<0.001$ ) and $25.7 \%$ (odds ratio for RR 3.10; $95 \%$ CI, 2.30 to 4.15 ) in the control group. No OS benefit was established. Grade 3 or higher adverse events of any cause occurred in $71.2 \%$ of patients in the study group and $71.5 \%$ of patients in the control group.

Checkmate 9ER [8] established the superiority of the combination of cabozantinib and nivolumab over sunitinib. Each of the three main endpoints routinely considered in oncology, for therapy decisions were improved. In addition the patient reported quality of life was also improved with the combination in comparison to sunitinib. The median PFS was 16.6 months and response rate was $55.7 \%$ with 
cabozantinib and nivolumab as compared to 8.3 months and $27.1 \%$ with sunitinib respectively. Severe adverse events were noted in $75.3 \%$ of the patients treated with cabozantinib and nivolumab and in $70.6 \%$ of patients treated with sunitinib.

The CLEAR trial [12] randomized patients with metastatic untreated renal cancer to lenvatinib+ pembrolizumab combination or lenvatinib and everolimus, each of which was compared to sunitinib. The lenvatinib and everolimus combination did not demonstrate a statistically significant benefit over sunitinib. However lenvatinib and pembrolizumab showed a median PFS of 23.9 months and response rate of $71 \%$ as compared to median of 9.2 months and $36.1 \%$ with sunitinib. OS benefit favoring Lenvatinib and pembrolizumab was noted with hazard ratio of $0.66, p=0.005$. 82.4\% of patients on Lenvatinib and pembrolizumab had adverse reactions reported.

\section{RATIONALE FOR CYTOREDUCTIVE NEPHRECTOMY IN ADVANCED RCC}

Several lines of evidence suggest that delayed CN after immunotherapy may be beneficial compared to immunotherapy alone and may provide the ideal combination of immune system priming as well as cytoreduction. The SurTime trial [7] was a randomized study comparing immediate versus delayed $\mathrm{CN}$ in patients with newly diagnosed $\mathrm{mRCC}$ treated with sunitinib. While not the primary endpoint, OS was significantly longer $(p=0.03)$ in patients undergoing delayed nephrectomy. A rational argument can be made that starting checkpoint-based immunotherapy prior to $\mathrm{CN}$ can generate a stronger immune response than upfront $\mathrm{CN}$ followed by immunotherapy. It is increasingly clear that immune responses develop against neoantigens resulting from patient-specific (i.e. private) mutations found in the tumor [16-19]. In a breast cancer animal model trial neoadjuvant immunotherapy produced a broader array of immune response as compared to the use of same therapy after resection of the primary tumor [17]. Checkpoint inhibitors work by "releasing" the immune response against mutations. In renal cancer it was demonstrated that surgical resection decreases PDL1 expression on tumor [19]. Consistent with this proposed mechanism, it has been reported that a greater mutational load contributed by the primary tumor predicts a stronger response to checkpoint inhibitors. Initial cytoreduction has the effect of surgically reducing the mutational load and decreasing the diversity of private mutations. Clonal evolution leads to tumor heterogeneity. The prevailing thought is that the most effective therapies will target the ubiquitous mutations in the "trunk" of the clonal evolutionary tree; however, initial cytoreduction tends to remove the largest source of ubiquitous mutations just prior to checkpoint inhibition, and prior to the greatest immune stimulation. After the immune stimulation has occurred, $\mathrm{CN}$ can remove a source of potential metastasis and immune suppression.

\section{SAFETY OF CN POST ICI THERAPY}

Performing surgery following checkpoint-based immunotherapy is expected to be safe. There is no mechanistic reason to be concerned about the safety of performing surgery in this setting. The SurTime trial (immediate versus delayed $\mathrm{CN}$ plus sunitinib) showed that $\mathrm{CN}$ following sunitinib therapy does not result in increased surgical complications and actually improves survival [7]. PROSPER (ECOG8143) is a phase III randomized trial of perioperative nivolumab versus observation for patients at high risk for recurrence following curative nephrectomy. Patients in the nivolumab arm received preoperative nivolumab and the study has completed accrual without any major safety concerns [20]. A phase II study of preoperative nivolumab for 3 doses was reported with no increased adverse events or complications noted [21]. Neoadjuvant axitinib was reported to show no increase in operative complications during nephrectomy [22]. A prospective pilot trial of presurgical ipilimumab designed to address safety did not uncover any concerns and the European Urology position paper has deemed nephrectomy after ICI therapy a safe procedure [23].

\section{CONCLUSIONS}

The role of cytoreductive nephrectomy for metastatic RCC is unclear in the era of immune-based therapies. There is evidence to suggest that starting with systemic therapy may help identify patients most likely to benefit from nephrectomy. The S1931/PROBE study is designed to evaluate the role of nephrectomy in impacting overall survival in patients who are treated with an immunotherapybased combination. The study addresses an important question within the context of contemporary management of synchronous metastatic kidney cancer. 


\section{ACKNOWLEDGMENTS}

The authors have no acknowledgments.

\section{FUNDING}

The authors report no funding.

\section{AUTHOR CONTRIBUTIONS}

U. Vaishampayan was responsible for drafting the manuscript, All authors had access to the data reviewed and provided input and editing of the content. Final draft was reviewed and approved by all authors.

\section{CONFLICTS OF INTEREST}

$\mathrm{HB}, \mathrm{BC}, \mathrm{SS}$ and HK report no conflicts of interest. UV received grant support from Merck, BMS and Exelixis, consulting fees and honoraria from Merck, BMS, Aveo, AAA, Bayer, Exelixis, Sanofi and Pfizer

UV is an Editorial Board Member of this journal, but was not involved in the peer-review process of this paper, nor had access to any information regarding its peer-review.

\section{REFERENCES}

[1] Flanigan RC, Yonover PM. The role of radical nephrectomy in metastatic renal cell carcinoma. Semin Urol Oncol. 2001;19:98-102.

[2] Mickisch GH, Garin A, van Poppel H, et al.; European Organisation for Research and Treatment of Cancer (EORTC) Genitourinary Group. Radical nephrectomy plus interferon-alfa-based immunotherapy compared with interferon alfa alone in metastatic renal-cell carcinoma: a randomised trial. Lancet. 2001;358:966-70.

[3] Flanigan RC, Mickisch G, Sylvester R, et al. Cytoreductive nephrectomy in patients with metastatic renal cancer: a combined analysis. J Urol. 2004;171:1071-6.

[4] Mejean A, Ravaud A, Thezenas S, et al. Sunitinib Alone or after Nephrectomy in Metastatic Renal-Cell Carcinoma. N Engl J Med. 2018;379(5):417-27.

[5] Albiges L, Tannir NA, Burotto M, et al. Nivolumab plus ipilimumab versus sunitinib for first-line treatment of advanced renal cell carcinoma: extended 4-year follow-up of the phase III CheckMate 214 trial. ESMO Open. 2020;5(6):e001079.

[6] Motzer RJ, Hutson TE, Tomczak P, et al. Sunitinib versus interferon alfa in metastatic renal-cell carcinoma. N Engl J Med. 2007;356:115-24.

[7] Bex A, Mulders P, Jewett M, et al. Comparison of Immediate vs Deferred Cytoreductive Nephrectomy in Patients With Synchronous Metastatic Renal Cell Carcinoma Receiving Sunitinib. The SURTIME Randomized Clinical Trial. JAMA Oncol. 2019;5(2):164-70.
[8] Choueiri T, Powles T, Burotto M, et al. Nivolumab plus Cabozantinib versus Sunitinib for Advanced Renal-Cell Carcinoma. N Engl J Med. 2021;384:829-41.

[9] Rini BI, Plimack E, Stus V, et al. Pembrolizumab plus Axitinib versus Sunitinib for Advanced Renal-Cell Carcinoma. N Engl J Med. 2019;380:1116-27.

[10] Motzer RJ, Renkov K, Haanen J, et al. Avelumab plus Axitinib versus Sunitinib for Advanced Renal-Cell Carcinoma. N Engl J Med. 2019;380:1103-15.

[11] Motzer RJ, Tannir N, McDermott DF, et al. Nivolumab plus Ipilimumab versus Sunitinib in Advanced Renal-Cell Carcinoma. N Engl J Med. 2018;378:1277-90.

[12] Motzer RJ, Alekseev B, Rha S, et al. Lenvatinib plus Pembrolizumab or Everolimus for Advanced Renal Cell Carcinoma. N Engl J Med. 2021;384:1289-300.

[13] Choueiri TK, Xie W, Kollmannsberger C, et al. The impact of cytoreductive nephrectomy on survival of patients with metastatic renal cell carcinoma receiving vascular endothelial growth factor targeted therapy. J Urol. 2011;185:60-6.

[14] Poprach A, Holanek M, Buchler T, et al. Cytoreductive Nephrectomy and Overall Survival of Patients with Metastatic Renal Cell Carcinoma Treated with Targeted Therapy-Data from the National Renis RegistryCancers (Basel). 2020;12(10):2911.

[15] Vaishampayan U, Vankayala H, Vigneau FD, et al. The effect of targeted therapy on overall survival in advanced renal cancer: a study of the national surveillance epidemiology and end results registry database. Clin Genitourin Cancer. 2014;12:124-9.

[16] Harshman LC, Drake CG, Haas NB. et al. Transforming the perioperative treatment paradigm in non-metastatic RCC a possible path forward. Kidney Cancer. 2017;1(1):31-40.

[17] Liu J, Blake SJ, Yong MC. et al. Improved efficacy of neoadjuvant compared to adjuvant immunotherapy to eradicate metastatic disease. Cancer Discov. 2016;6(12):1382-99.

[18] Dadian G, Riches PG, Henderson DC, et al. Immunological parameters in peripheral blood of patients with renal cell carcinoma before and after nephrectomy. Br J Urol. 1994;74:15-22.

[19] MacFarlane AW IV, Jillab M, Plimack ER, et al. PD-1 expression on peripheral blood cells increases with stage in renal cell carcinoma patients and is rapidly reduced after surgical tumor resection. Cancer Immunol Res. 2014;2:320-31.

[20] Harshman LC, Puligandla M, Haas NB, et al. PROSPER: A phase III randomized study comparing perioperative nivolumab (nivo) versus observation in patients with localized renal cell carcinoma (RCC) undergoing nephrectomy (ECOG-ACRIN 8143). Journal of Clinical Oncology. 2019;37(7_suppl):TPS684-TPS684.

[21] Gorin MA, Patel HD, Rowe SP, Hahn NM, Hammers HJ, Pons A, Trock BJ, Pierorazio PM, Nirschl TR, Salles DC, Stein JE, Lotan TL, Taube JM, Drake CG, Allaf ME. Neoadjuvant Nivolumab in Patients with High-risk Nonmetastatic Renal Cell Carcinoma. Eur Urol Oncol. 2021;:S2588-9311(21)00076-6

[22] Karam JA, Devine CE, Urbauer DL, Lozano M, Maity T, Ahrar K, Tamboli P, Tannir NM, Wood CG. Phase 2 trial of neoadjuvant axitinib in patients with locally advanced nonmetastatic clear cell renal cell carcinoma. Eur Urol. 2014;66(5):874-80.

[23] Grimm MO, Bex A, De Santis M, Ljungberg B, et al. Safe Use of Immune Checkpoint Inhibitors in the Multidisciplinary Management of Urological Cancer: The European Association of Urology Position in 2019. Eur Urol. 2019;76(3):368-80. 